\title{
Os porquês de uma política nacional de mídia-educação'
}

Alexandra Bujokas de Siqueira

Doutora em Educação pela Universidade Estadual de São Paulo (UNESP), com pós-doutorado em Estudos de Mídia pela Open University, na Inglaterra. Professora da Universidade Federal do Triângulo Mineiro.

E-mail: bujokas@uol.com.br

Guilherme Canela

Mestre em Ciência Política pela Universidade de São Paulo. Assessor de Comunicação e Informação para o Mercosul e Chile da Organização das Nações Unidas para a Educação, a Ciência e a Cultura (Unesco).

E-mail: guilherme.godoi@unesco.org.br

Resumo: O objetivo deste artigo é oferecer um panorama conceitual que fundamente iniciativas internacionais na promoção de políticas de media literacy que incluam a promoção de habilidades para acessar, avaliar e usar as novas e velhas mídias, integrando o desenvolvimento de habilidades técnicas, culturais e políticas. Para tanto, o texto recupera iniciativas da Unesco dos anos 1980 até o presente momento, complementando esse cenário com a descrição de ações da União Europeia e do Office of Communications, órgão regulador da mídia britânica. Ao final, apresenta o modelo curricular da Unesco para a formação de professores em Alfabetização Midiática e Informacional.

Palavras-chave: Media literacy, mídia-educação, políticas públicas, formação de professores, currículo.
Abstract: This paper aims to provide a conceptual overview that supports international initiatives to promote media literacy policies, which include the promotion of abilities to access, evaluate and use both new and old media, connecting the development of technical, cultural and political skills. In doing so, it retrieves UNESCO initiatives, from the early 80 s to the present, and also complements the scenario with the actions carried out by the European Union and the Office of Communications, the British media regulator. At the end, the paper presents the UNESCO's curriculum for teacher training in media and Information Literacy.

Keywords: Media literacy, media education, public policies, teacher training, curriculum.

\section{INTRODUÇÃO}

Vivemos um momento em que as escolas precisam de políticas nacionais de mídia-educação, e não é difícil apontar razões para isso. As mídias estão diluídas na nossa experiência cotidiana, no trabalho, estudo e lazer. O uso que fazemos delas ora nos caracteriza como leitores, ouvintes e espectadores ${ }^{2}$, ora como escritores e produtores de conteúdo. Independentemente da nossa 
comunicação \& educação • Ano XVII • número 2 • jul/dez 2012

2. Internacionalmente, vem sendo usado o termo multiliteracies para se referir às habilidades de leitura e escrita que emergem com a popularização das mídias digitais. Para alguns pesquisadores entretanto, é só uma questão de tempo até que as qualificações das multiliteracies desapareçam como formas digitais específicas e se integrem ao conceito mais amplo e mais simples de leitura. Aqui, iremos nos referir à media literacy e leitura como esse conjunto maior de habilidades para ler e produzir conteúdo, usando a linguagem verbal as linguagens não verbais.

3. Media literacy é o termo em inglês que tem sido usado para caracterizar o conjunto de habilidades e competências necessárias para se viver e trabalhar no contexto contemporâneo marcado pela popularização das tecnologias de comunicação e informação.

4. O Office of Communications (Ofcom) é um órgão regulador da mídia britânica criado com a Lei de Comunicações de 2003 motivação inicial - compartilhar um vídeo com os amigos ou adaptar uma apresentação para a linguagem audiovisual -, nossa produção é geralmente amadora, isto é, motivada por interesses pessoais e sem intenção de lucro. Produtores amadores, em geral, não possuem uma visão "de dentro" do sistema de produção midiática - e é esse o mecanismo que explica, em parte, por que os filmes ou as notícias são como são.

Talvez um dos mais reveladores aspectos da comunicação midiática seja a presença das relações de poder na produção de conteúdos. Sem formular juízos de valor, precisamos conhecer essas interações, sob pena de sermos prejudicados no exercício de nosso direito de acesso à informação e liberdade de expressão.

Em palestra proferida no Fórum Internacional de Pesquisa em media literacy $^{3}$, promovido pelo Ofcom ${ }^{4}$ britânico, a professora Sonia Livingstone, da London School of Economics e Policital Science, destacou as relações de poder entre "a grande mídia e o pequeno público" - uma imagem contraditória, já que o público é fisicamente maior que os proprietários e seus profissionais. E que poder é esse?

Numa definição elementar, poderíamos dizer que poder se refere à capacidade de exercer influência. Nas sociedades contemporâneas, identificamos três formas básicas de poder social: o econômico (capacidade de mobilizar dinheiro), o político (capacidade de estabelecer leis, vigilância e punição) e o simbólico (capacidade de mobilizar e valorizar ideias).

Todas as instituições sociais exercem uma ou mais formas de poder. Também a mídia mobiliza dinheiro e ideias, vigia, agenda e, em certa medida, pune. Na relação da mídia com o público, vemos uma enorme assimetria entre as capacidades de mobilização: a audiência influencia a permanência ou não de um programa, mas não é menos verdade que as escolhas do público estão limitadas ao leque de opções ofertadas. A longo prazo, tal assimetria gera desigualdades de acesso à informação relevante.

Uma forma de enfrentar as assimetrias é o estabelecimento de políticas de regulação, segundo as regras do jogo em um Estado democrático de direito. Políticas desse tipo objetivam criar mecanismos de regulação independentes do governo ou de pressões corporativas, fomentar o desenvolvimento de sistemas de mídia públicos, comerciais e comunitários, e conferir aos usuário, poderes para fazer uso crítico e autônomo dos meios de comunicação, bem como exercer a defesa qualificada da liberdade de expressão como elemento central para o desenvolvimento das democracias. Este último aspecto - o do "empoderamento do público" - compõe a base das ações de educação para a mídia.

\section{MEDIA LITERACY E FORMAÇÃO DO JOVEM}

A mídia para o público jovem envolve questões específicas. No contexto contemporâneo, a ideia de infância está colocada em cartas de direito como a Convenção Internacional sobre os Direitos da Criança, aprovada pela 
Organização das Nações Unidas, e o Estatuto da Criança e do Adolescente, no Brasil - que expressam os anseios das nações em relação a indivíduos de determinados limites etários. Uma vez estabelecidos os princípios e direitos para a infância, as nações passam - ou deveriam passar - a ter, como preocupação central, colocar em prática tais enunciados nos espaços em que suas crianças se desenvolvem ${ }^{5}$. Sendo os meios de comunicação instituições fundamentais no processo de socialização da infância, torna-se indispensável a oferta, pelo Estado, de instrumentos alinhados à promoção de direitos, além da regulação daqueles que apresentem potencial risco em contrário.

Intrínseca a esta discussão é a perspectiva de que a regulação da mídia não se dê somente a partir da ideia de que os conteúdos audiovisuais apresentam riscos ao desenvolvimento da população infantojuvenil. Em outras palavras, é preciso também atentar aos benefícios auferidos da interação com a mídia. $\mathrm{O}$ binômio proteger-promover, portanto, surge como paradigma contemporâneo para a mídia-educação, tendo, entre seus objetivos, formar leitores e produtores críticos e autônomos.

\section{O QUE SIGNIFICA SER LEITOR CRÍTICO DA MÍDIA}

Enquanto um leitor ingênuo vê as mensagens midiáticas como uma analogia da realidade - e, portanto, a mensagem como um veículo para a verdade dos fatos -, um leitor crítico, por sua vez, compreende o que vê como resultado de processo de produção; e a mensagem, por sua vez, como produto de relações de força que geram significado. Nesse contexto, a tarefa da educação para a mídia é criar oportunidades para que o público conheça os meandros da produção profissional de mensagens em larga escala, bem como o modo pelo qual ela mobiliza sua própria formação de valores. Alcançado esse objetivo, sua interação com as mídias (e vice-versa) ganha em qualidade, assim como a percepção dos cidadãos quanto à centralidade da liberdade de expressão e ao direito à informação para a consolidação das democracias.

Qualquer que seja a iniciativa ligada à educação para as mídias, é preciso uma definição do que seja um leitor crítico e autônomo para o planejamento de estratégias afinadas a esse perfil.

Na Europa, em 2004, Áustria, Bélgica, França, Alemanha, Portugal, Espanha, Suécia e Reino Unido assinaram o European Charter for Media Literacy, no qual sintetizam uma ideia comum desse leitor:

Acreditamos que as pessoas detentoras de uma literacia dos media devem ser capazes de:

- Usar eficazmente as tecnologias dos media para aceder, guardar, reencontrar e partilhar conteúdos que vão ao encontro dos interesses e necessidades individuais e da sua comunidade;

- Ter acesso e efetuar escolhas informadas sobre um vasto leque de formas e conteúdos mediáticos provenientes de fontes culturais e institucionais variadas;

5. CANELA, Guilherme; AGÊNCIA DE NOTÍCIAS DOS DIREITOS DA INFÂNCIA. Regulação de Mídia e Direitos das Crianças e Adolescentes: uma análise do marco legal de 14 países latino-americanos, sob a perspectiva da promoção e proteção. Brasília: ANDI ‘ 2008. 
comunicação \& educação • Ano XVII • número 2 • jul/dez 2012

- Compreender como são produzidos conteúdos mediáticos e por quê, assim como os contextos tecnológicos, legais, políticos e econômicos dessa produção;

- Analisar criticamente as técnicas, linguagens e convenções usadas pelos media e as mensagens que estes veiculam;

- Usar criativamente os media para expressar e comunicar ideias, informações e opiniões;

- Identificar e evitar, ou confrontar, conteúdos e serviços mediáticos que possam ser indesejados, ofensivos ou prejudiciais;

- Fazer um uso eficaz dos media no exercício dos seus direitos democráticos e responsabilidades cívicas ${ }^{6}$.

O Ofcom britânico também tem uma definição de leitor crítico e autônomo para embasar as políticas de media literacy executadas no país desde 2003, quando foi aprovado o Communications Act 2003, que atribui àquela instituição a tarefa de promover a compreensão pública do papel social e do funcionamento da mídia:

Media literacy tem paralelos com a leitura tradicional, a habilidade para ler e escrever. Assim, media literacy é a habilidade para ler e escrever informação audiovisual ao invés de texto. No nível mais simples, media literacy é a habilidade para usar uma variedade de mídias e ser capaz de compreender a informação recebida. Em um nível mais avançado, a habilidade de ler se move do simples reconhecimento e compreensão para uma ordem mais elevada de habilidades de pensamento crítico, tais como saber questionar, analisar e avaliar a informação. Este aspecto da media literacy é algumas vezes descrito como "visão crítica" ou "análise crítica”. (...) Pessoas letradas em mídia (...) deveriam saber reconhecer em que medida o produtor está tentando influenciá-las de alguma forma. Elas deveriam também ser capazes de usar as tecnologias de comunicação para criar seus próprios conteúdos em áudio e vídeo 7 .

6. EUROPEAN CHARTER FOR MEDIA LITERACY. Carta europeia para uma literacia dos media. Disponível em: <http:// www.euromedialiteracy. eu/charter. php?id=4> Acesso em: 27 jul. 2010.

7. OFFICE OF COMMUNICATIONS (2009). What is media literacy [O que é media literacy]. Disponível em: <http://stakeholders. ofcom.org.uk/ market-data-research/media-literacy/about/whatis/>. Acesso em: 27 jul. 2010.

8. MARTINSSON, Johanna. The role of media literacy in the governance reform agenda [O papel da media literacy na agenda da reforma governamental]. Washington: The World Bank, 2009. p. 3.
De modo geral, as habilidades de media literacy requerem três capacidades básicas: saber acessar mensagens; saber avaliar a qualidade da informação e saber produzir conteúdos usando diversas linguagens e plataformas. De posse dessas habilidades, os cidadãos podem se relacionar melhor com a mídia e, conforme Martinsson ${ }^{8}$, aprimorar o pensamento crítico e a autonomia, solucionar problemas e desenvolver habilidades mais sofisticadas de comunicação e expressão, construindo assim uma cidadania ativa e informada.

\section{POLÍTICAS PÚBLICAS PARA A MÍDIA-EDUCAÇÃO}

Colocar tal proposta em prática requer o desenho de uma ampla política que envolva as esferas pública federal, estatal e local, além da esfera privada e da sociedade civil organizada para:

- baratear os equipamentos;

- prover redes e outros serviços de acesso com custos compatíveis à renda per capita dos diversos segmentos da população; 
- promover a educação para operar sistemas tecnológicos;

- criar mecanismos de proteção de grupos vulneráveis;

- criar mecanismos para a autorregulação.

Do mesmo modo, fomentar o desenvolvimento da capacidade de avaliação implica promover:

- educação para decodificar mensagens;

- criação de canais institucionais para onde o público possa dirigir reclamações;

- criação de parâmetros objetivos e independentes para a recuperação e avaliação de conteúdos quando uma reclamação é registrada;

- oferta de infraestrutura pedagógica: fomento à produção de materiais específicos sobre mídia-educação, cursos para professores e disponibilização de acervos com direitos autorais específicos para a apropriação de conteúdos.

Por fim, antes e para fomentar a produção de conteúdos, é necessário:

- ter à disposição canais públicos e comunitários através dos quais possa ser veiculada a produção do público;

- ter políticas de incentivo à produção independente;

- ter políticas de incentivo à produção de caráter comunitário;

- promover uma reforma curricular que inclua as mídias digitais no trabalho cotidiano das escolas;

- ter investimentos públicos para fomentar o desenvolvimento de uma cultura digital escolar.

Assas ações contribuem para formar o ecossistema midiático comprometido com a liberdade de expressão e com o Estado de direito democrático, conforme descrito por Martín-Barbero ${ }^{9}$.

\section{A PROPOSTA DA UNESCO}

O cenário descrito indica que é preciso conceber a educação para a mídia como componente de uma política ampla que a Unesco chama de "desenvolvimento da mídia”:

O corolário dessa análise é a necessidade da intervenção estatal no sentido de promover um ambiente de mídia caracterizado pela liberdade de expressão, pelo pluralismo e pela diversidade, com a definição pormenorizada de leis de restrição da liberdade da mídia, limitadas àquelas necessárias a uma democracia, e com dispositivos legais que assegurem igualdade de condições no plano econômico. Tudo isso requer dispositivos para a mídia pública e comunitária e, também, para a mídia privada ${ }^{10}$.

A visão sistêmica da estrutura de comunicação midiática de um país nos indica caminhos por onde podemos desenvolver ações de educação para a mídia. É preciso encontrar formas de ensinar questões de caráter técnico, estético, cultural e político.

9. MARTÍN-BARBERO, Jesús. La educación desde la comunicación [A educação a partir da comunicação]. Buenos Aires: Grupo Editorial Norma, 2002.

10. UNESCO; INTERNATIONAL EXPERT GROUP. Indicadores de desenvolvimento de mídia: marco para avaliação do desenvolvimento dos meios de comunicação. Brasília: Unesco, 2010. p. 4. 
11. Id. Teacher training curricula for media and information literacy: background strategy paper [Currículos de treinamento para professores em media e information literacy; carta estratégica de background]. Paris: Unesco, 2008. p. 5.

12. GRUNWALD. Declaration on Media Education [Declaração Grunwald de mídia educação]. Disponivel em: <http://www. UNESCO.org/education/ pdf/MEDIA_E.PDF> Acesso em: 5 ago. 2010.

13. UNESCO; INTERNA TIONAL Expert Group. Teacher training curricula for media and information literacy: background strategy paper [Currículos de treinamento para professores em media e information literacy: carta estratégica de background]. Paris: Unesco, 2008 comunicação \& educação • Ano XVII • número 2 • jul/dez 2012

A Unesco, no escopo do programa Information and Media Literacy, estabeleceu quatro ações estratégicas:

1. Promover melhor compreensão do funcionamento da mídia, seu potencial e suas limitações;

2. Promover o pensamento crítico, a autonomia e a iniciativa para lidar com as mensagens;

3. Fortalecer as capacidades, os direitos e as responsabilidades dos indivíduos em congruência com as capacidades, os direitos e as responsabilidades dos meios;

4. Facilitar o acesso, o uso criativo e produtivo das tecnologias de comunicação e informação ${ }^{11}$.

Essas ações vêm sendo implementadas em diversos países e acompanhadas pela UNESCO há mais de 25 anos. Um marco importante foi o Simpósio Internacional sobre Mídia-Educação ${ }^{12}$, realizado em Grunwald, Alemanha, em 1982. Ao final do evento, os participantes elaboraram uma declaração clamando as autoridades competentes de cada país a:

1. Lançar e dar suporte a amplos programas de mídia-educação, da educação infantil à universidade e, também, na educação de adultos;

2. Incentivar o desenvolvimento da consciência crítica, promovendo competências para o uso das mídias impressa e eletrônica, incluindo habilidades de análise das mensagens, produção criativa e formas de participação em canais já existentes;

3. Desenvolver cursos para professores que, ao mesmo tempo, ampliem o conhecimento sobre os meios de comunicação e ensinem métodos pedagógicos apropriados para se usar mídias na educação, levando em conta a experiência dos estudantes;

4. Estimular a pesquisa que beneficie a mídia-educação em domínios tais como a Psicologia, a Sociologia e as Ciências da Comunicação;

5. Apoiar ações da Unesco que têm como objetivo fomentar a cooperação internacional para promover a mídia-educação.

Outras conferências sobre o tema foram realizadas em Toulouse, na França, em 1990; em Viena, na Áustria, em 1998; em Sevilha, na Espanha, em 2000; em Paris, em 2005; em Ryidah, no Oriente Médio, em 2006; e novamente em Paris, em 2007. Tais conferências embasaram a produção de outros documentos voltados a essas questões.

Em 2008, um grupo de experts se reuniu em Paris para discutir as bases de um referencial curricular para a formação de professores, gerando um relatório ${ }^{13}$ que delineou temas e competências básicas de um educador hábil a usar as mídias. O quadro 1 apresenta os tópicos selecionados.

Em 2011, a Unesco lançou a versão final do documento Media and Information Literacy Curriculum for Teachers ${ }^{15}$ ou Alfabetização Midiática e Informacional - Currículo para Formação de Professores, com versão em português a ser lançada pela Universidade Federal do Triângulo Mineiro (UFTM) em 2012. 


\begin{tabular}{|c|c|}
\hline TEMA & DESCRIÇÃO \\
\hline \multicolumn{2}{|c|}{ 1. TEMAS PARA FORMAR O REPERTÓRIO DO PROFESSOR } \\
\hline $\begin{array}{l}\text { Mídia e discurso } \\
\text { democrático }\end{array}$ & $\begin{array}{c}\text { Liberdade de expressão, pluralismo e diversidade na mídia; } \\
\text { transparência e propriedade; mídia como plataforma para o } \\
\text { discurso democrático; profissionalismo na mídia (jornalismo, } \\
\text { ética); infraestrutura capaz de dar suporte ao pluralismo e à } \\
\text { diversidade. }\end{array}$ \\
\hline $\begin{array}{l}\text { Análise de textos } \\
\text { midiáticos }\end{array}$ & $\begin{array}{l}\text { Processos de construção de textos midiáticos; códigos } \\
\text { e convenções que formam a "gramática da mídia"; } \\
\text { representação, identidades e estereótipos; estruturas } \\
\text { narrativas, vozes, inclusão e exclusão de informações. }\end{array}$ \\
\hline $\begin{array}{l}\text { Compreensão do papel } \\
\text { social da mídia }\end{array}$ & $\begin{array}{l}\text { Propósitos subjacentes à comunicação midiática, discurso } \\
\text { e persuasão; informação, educação, entretenimento e } \\
\text { propaganda; avaliação de fontes, autoridade e precisão das } \\
\text { informações veiculadas. }\end{array}$ \\
\hline Audiências & $\begin{array}{l}\text { Conceito de público-alvo; audiências ativas (interpretação, } \\
\text { negociação, avaliação, acesso e uso). }\end{array}$ \\
\hline $\begin{array}{l}\text { Produção de conteúdo por } \\
\text { parte das corporações de } \\
\text { mídia }\end{array}$ & $\begin{array}{c}\text { Como as corporações de mídia operam; direitos e } \\
\text { responsabilidades, liberdade de expressão; indústria cultural, } \\
\text { propriedade e regulação. }\end{array}$ \\
\hline $\begin{array}{l}\text { Produção de conteúdo por } \\
\text { parte do público }\end{array}$ & $\begin{array}{l}\text { Como criar e divulgar suas próprias mensagens; uso de } \\
\text { tecnologias de comunicação e informação; valores éticos, } \\
\text { autonomia pessoal e participação na esfera pública; } \\
\text { promoção do diálogo intercultural. }\end{array}$ \\
\hline Produção técnica & $\begin{array}{c}\text { Uso das TICs (Tecnologias da Informação e Comunicação) na } \\
\text { educação. }\end{array}$ \\
\hline \multicolumn{2}{|c|}{ 2. TEMAS PARA FORMAR O PROFESSOR PARA ENSINAR SOBRE MÍDIA } \\
\hline Design instrucional & $\begin{array}{l}\text { Desenvolvimento de atividades curriculares para ensinar } \\
\text { educação para a informação e comunicação; adaptação e } \\
\text { desenvolvimento de recursos educacionais e amostras de } \\
\text { mídia; criação e desenvolvimento de recursos para o trabalho } \\
\text { cooperativo, através das tecnologias de comunicação e } \\
\text { informação; uso de métodos de questionamento e solução } \\
\text { de problemas; desenvolvimento de métodos adequados de } \\
\text { avaliação das atividades. }\end{array}$ \\
\hline $\begin{array}{c}\text { Mudanças no setor } \\
\text { educacional em função das } \\
\text { mídias }\end{array}$ & $\begin{array}{l}\text { Mudanças no papel do professor; implementação do currículo } \\
\text { e mudanças na gestão; criação de ambientes escolares que } \\
\text { dão suporte à educação para a informação e comunicação. }\end{array}$ \\
\hline
\end{tabular}

Quadro 1: Temas de mídia-educação para compor um referencial curricular para a formação de professores ${ }^{14}$.

A primeira parte da proposta curricular descreve as competências básicas para acessar, avaliar, usar e produzir conteúdos usando as mídias, bem como formas de integrar essas competências aos currículos de formação de professores. Apresenta, também, dez técnicas pedagógicas que facilitam seu ensino e aprendizagem. A segunda parte reúne onze módulos que sintetizam conceitos relevantes para orientar o estudo da mídia, tais como liberdade de expressão,

14. Ibid. (Tradução nossa.) 15. Id. Media and Information Literacy Curriculum for Teachers [Alfabetização midiática e informacional: currículo para formação de professores]. Paris: Unesco, 2011. Disponível em: <http:// unesdoc.UNESCO.org/ images/0019/001929/ 192971 e.pdf $>$. Acesso em: 30 abr. 2012 
comunicação \& educação • Ano XVII • número 2 • jul/dez 2012

ética e responsabilização da mídia, audiências, publicidade, sistemas de produção de notícias e linguagem e representação.

De modo geral, o referencial curricular foca o desenvolvimento da consciência na maneira pela qual usamos as mídias. A mídia-educação é considerada um instrumento para construir sociedades do conhecimento e promover a liberdade de expressão e o acesso à informação.

A proposta é que universidades brasileiras implementem projetos-piloto integrando a educação para a informação e comunicação na formação inicial de professores para o Ensino Médio, através de um referencial curricular adaptável em todo o mundo. Na perspectiva da Unesco, trata-se de uma proposta que não só aborda as questões de mídia, mas facilita a integração de outras áreas do currículo à leitura, produção e participação cidadã, que emerge da disseminação das tecnologias de comunicação e informação.

\section{CONSIDERAÇÕES FINAIS}

O relativo insucesso de políticas de mídia-educação nos últimos anos deve-se, em muito, à incapacidade de se resolver a equação: "muito hardware, pouco software versus muito software, pouco hardware". As políticas de mídia-educação se concentravam em um ensino majoritariamente conceitual e teórico, sem que os aprendizes pudessem ter uma consciência real do que significava "fazer mídia".

Da mesma forma, é comum que a introdução das chamadas tecnologias da informação e comunicação no ambiente escolar se dê por meio do uso mecanizado da ferramenta tecnológica, sem aprofundamento sobre o significado social das TICs para as sociedades da informação e do conhecimento.

$\mathrm{O}$ ponto de equilíbrio está em viabilizar iniciativas que integrem habilidades técnicas, para operar as ferramentas, e também culturais, para analisar, compreender, valorizar, criticar e usar as novas e velhas mídias - integrando-as às perspectivas sociais, políticas, culturais e econômicas das sociedades contemporâneas. A inclusão dessas questões na formação das novas gerações de educadores será decisiva para criar um ecossistema midiático que, ao mesmo

16. SALOMON, Eve. The role of broadcasting regulation in media literacy [O papel da regulação da radiodifusão na media literacy]. In: ONU; UNESCO; ALLIANCE OF CIVILIZATIONS/GRUPO COMUNICAR. Mapping media education policies in the world [Mapeando as políticas de mídia-educação no mundo]. Nova York: ONU, 2009. p. 202. tempo, reflita os padrões aceitos e também as expectativas da diversidade de públicos - resultado de uma sociedade consciente do papel social dos meios de comunicação, que cobraria do Estado seu papel regulador, criando o ciclo virtuoso descrito por Salomon ${ }^{16}$ : "o público diz ao órgão regulador o que eles querem, o regulador codifica as expectativas em um regulamento e as corporações de mídia, seguindo as regras, entregam ao público o que ele tem expectativa de ver".

Quando este ciclo é consolidado, os cidadãos letrados em mídia são capazes de garantir que a qualidade dos conteúdos e processos de comunicação se mantenham elevados. 


\section{REFERÊNCIAS BIBLIOGRÁFICAS}

CANELA, Guilherme. AGÊNCIA DE NOTÍCIAS DOS DIREITOS DA INFÂNCIA. Regulação de Mídia e Direitos das Crianças e Adolescentes: uma análise do marco legal de 14 países latino-americanos, sob a perspectiva da promoção e proteção. Brasília: ANDI, 2008.

MARTÍN-BARBERO, Jesús. La educación desde la comunicación [A educação a partir da comunicação]. Buenos Aires: Grupo Editorial Norma, 2002.

MARTINSSON, Johanna. The role of media literacy in the governance reform agenda [O papel da media literacy na agenda da reforma governamental]. Washington: The World Bank, 2009.

SALOMON, Eve. The role of broadcasting regulation in media literacy [O papel da regulação da radiodifusão na media literacy]. In: ONU; UNESCO; ALLIANCE OF CIVILIZATIONS/GRUPO COMUNICAR. Mapping media education policies in the world [Mapeando as políticas de mídia-educação no mundo]. Nova York: ONU, 2009.

UNESCO; INTERNATIONAL EXPERT GROUP. Teacher training curricula for media and information literacy: background strategy paper [Currículos de treinamento para professores em media e information literacy - carta estratégica de background]. Paris: Unesco, 2008.

Indicadores de desenvolvimento de mídia: marco para avaliação do desenvolvimento dos meios de comunicação. Brasília: Unesco, 2010.

\section{Endereços eletrônicos}

EUROPEAN CHARTER FOR MEDIA LITERACY. Carta europeia para uma literacia dos media. Disponível em: <http://www.euromedialiteracy.eu/charter. php?id=4>. Acesso em: 27 jul. 2010.

GRUNWALD. Declaration on Media Education [Declaração Grunwald de mídia educação]. Disponível em <http://www.UNESCO.org/education/pdf/ MEDIA_E.PDF $>$. Acesso em: 5 ago. 2010.

OFFICE OF COMMUNICATIONS (2009). What is media literacy [O que é media literacy]. Disponível em: <http://stakeholders.ofcom.org.uk/ market-dataresearch/media-literacy/about/whatis/>. Acesso em: 27 jul. 2010.

UNESCO; INTERNATIONAL EXPERT GROUP. Media and Information Literacy

Curriculum for Teachers [Alfabetização midiática e informacional: currículo para formação de professores]. Paris: Unesco, 2011. Disponível em: <http://unesdoc. unesco.org/images/0019/001929/192971e.pdf>. Acesso em: 30 abr. 2012. 


\section{Curso de Especialização em Educomunicação}

cca

eca

usp

\section{curso de especialização lato sensu}

\section{- Departamento de Comunicações e Artes da ECA/USP abre inscrições} para a primeira turma de especialização lato sensu em Educomunicação

\section{Habilidades do Educomunicador}

- Desenvolver uma leitura crítica da mídia.

- Dominar a pedagogia do tratamento da comunicação no espaço escolar, tanto como conteúdo didático quanto como processo a ser adotado.

- Ampliar o coeficiente comunicativo das ações educativas, garantindo as diferentes formas de expressão por parte dos polos vivos no ecossistema escolar, valorizando especialmente a mediação artística.

- Implementar trabalhos colaborativos de produção midiática utilizando os recursos da informação e da comunicação em processos educativos.

- Implementar estratégias de planejamento, gestão e avaliação de planos, programas e projetos na área da comunicação/ educação em espaços educativos.

- Entender e interferir nas políticas públicas que legitimam a educomunicação como nova área de intervenção social nos espaços educativos.

\section{Processo Seletivo Semestral}

Duração: três semestres

Pré-requisito: formação superior em

qualquer área do saber.

Seleção: prova escrita, entrevista

\section{Mais informações www.cca.eca.usp.br}

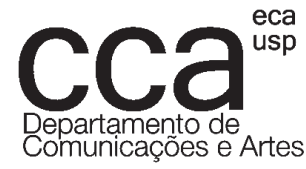

Comunicações e Artes

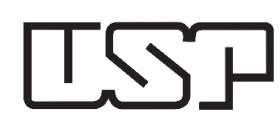

Endereço

Av. Prof. Lúcio Martins

Rodrigues, 443, sl 209

Cidade Universitária

São Paulo - SP
Contato

$\left(+551^{\circ)} 3091-4341\right.$

(+551 ) 3091-4867

www.cca.eca.usp.br 